\title{
Isolated gastric tear due to blunt abdominal trauma
}

\section{Y Saifee, U Shrivastava, S Gupta, A Thakral}

\section{Citation}

Y Saifee, U Shrivastava, S Gupta, A Thakral. Isolated gastric tear due to blunt abdominal trauma. The Internet Journal of Gastroenterology. 2008 Volume 7 Number 2.

\section{DOI: $\underline{10.5580 / 28 c 5}$}

\begin{abstract}
A 7 years old child presented with a history of be fall from a height(10 ft approx). The child had ingested a large meal in the hour preceding the injury. He complained of generalized pain in the the abdomen. He was haemodynamically stable. Abdominal examination was unremarkable initially but soon child developed abdominal distension \& generalized tenderness. $X$ ray abdomen(erect) showed gas under diaphragm. Ultrasound abdomen did not show any solid organ injury. At laparotomy the only injury found was a complete tear of the greater curvature of stomach. The tear was sutured and the patient made an uneventful recovery.
\end{abstract}

\section{INTRODUCTION}

In blunt abdominal trauma incidence of injury to the solid organs is much higher than that to the hollow viscus nonoperative management of solid organ injury from blunt trauma in children has focused concern on potential delays in diagnosis of hollow viscus injury with resultant increases in morbidity, mortality, and $\operatorname{cost}_{1}$.

\section{CASE REPORT}

A 7 years old child presented with a history of be fall from a height(10 ft approx). The child had ingested a large meal in the hour preceding the injury. He complained of generalized pain in the the abdomen. He was haemodynamically stable. Abdominal examination was unremarkable initially but soon child developed abdominal distension \& generalized tenderness. X ray abdomen(erect) showed gas under diaphragm. Ultrasound abdomen did not show any solid organ injury. At laparotomy the only injury found was a complete tear of the greater curvature of stomach. The tear was sutured and the patient made an uneventful recovery.

\section{Figure 1}

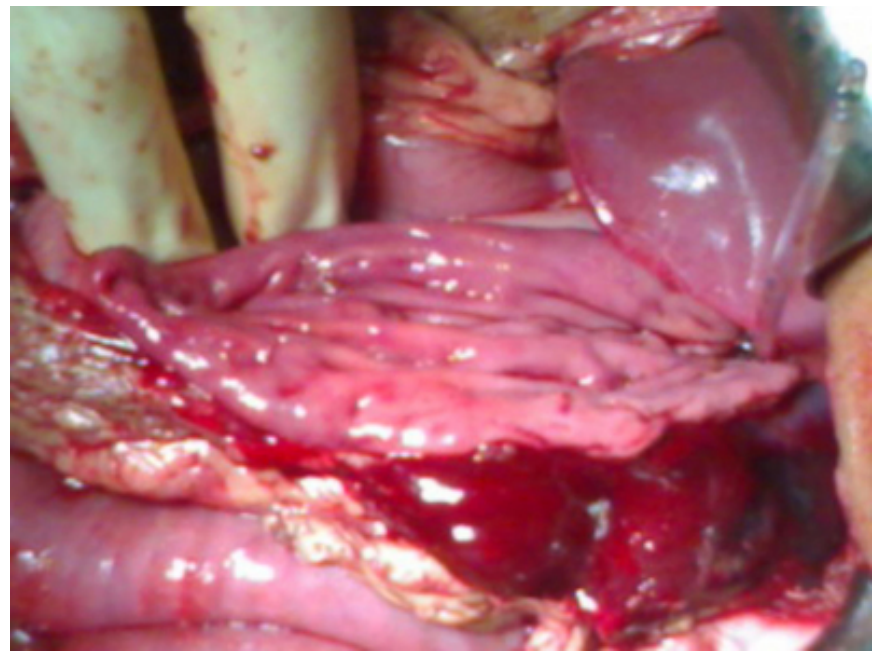




\section{Figure 2}

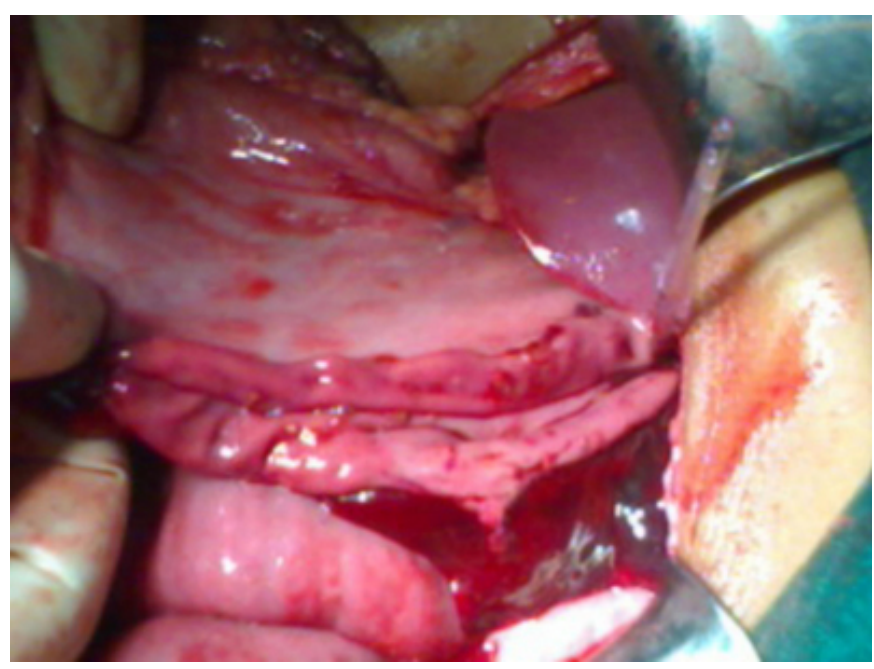

DISCUSSION

Injuries to the stomach are very rare in blunt abdominal trauma. ${ }_{1}$ The stomach has very strong walls and these are not torn by blunt trauma unless it is very severe or the stomach is full, or both. Such trauma commonly involves adjacent organs like the liver, spleen, and pancreas. ${ }_{2}$ Apart from injuries to the anterior gastric wall, total rupture of the gastro-oesophageal junction, ${ }_{3}$ complete circular avulsion of the stomach from the duodenum, ${ }_{4}$ and rupture of both the gastric walls ${ }_{5}$ have been reported due to blunt abdominal trauma. All of these were associated with a solid organ injury.
In our case there was an injury only to the greater curvature of stomach. There was no other intra-abdominal injury. We, after extensive literature search, believe that this is the only case of isolated greater curvature of stomach injury being reported. The most probable mechanism of injury in this patient was injury on a full stomach. Initial clinical and radiological evidence of bowel perforation can be misleading and reliance on such indicators may result in significant diagnostic delay. Frequently repeated clinical examination is advocated; progression of abdominal signs should alert the clinician to proceed to laparotomy.

\section{CORRESPONDENCE TO}

Dr. Yusuf ali saifee 122 C, Pocket A Dilshad GardenDelhi-95 Phone: 09810836552 Email:

Yusuf.Saifee@gmail.com doc_yusuf@rediffmail.com

\section{References}

1. Hoyt DB, Moosa AR. Abdominal injuries. In: Cuschieri A, Giles GR, Moosa AR, eds. Essential surgical practice. Oxford: Butterworth-Heinemann, 1995:531-44.

2. Wilkinson AE. Injuries of stomach. An analysis of 95 cases. S Afr J Surg 1989;27:59-60.

3. Fernandez-Llamagares J, Moreno P, Garcia F, et al. Total rupture of the gastro-oesophageal junction after blunt trauma. Eur J Surg 1999;165:73-4.

4. Kolibaba SS, Shevnia PS, Khimich SD, et al. Severe closed trauma to abdomen with complete circular avulsion of stomach from duodenum and rupture of spleen and oesophagus. [In Russian]. Klin Khir 1992;4:67-8.

5. Zarowski L, Gutkowski R, Kalemba M. Rupture of both gastric walls after blunt abdominal injury. [In Polish]. Waiadomosci Lekarskie 1980;33:1255-6. 


\title{
Author Information
}

Yusuf Ali Saifee, MBBS,MS

Senior Resident, Department of Surgery, University College of Medical Sciences \& Guru Teg Bahadur Hospital

\section{U.K. Shrivastava}

Professor \& Unit Head, Department of Surgery, University College of Medical Sciences \& Guru Teg Bahadur Hospital, Delhi

\section{Sanjay Gupta}

Professor, Department of Surgery, University College of Medical Sciences \& Guru Teg Bahadur Hospital

\author{
Ajay Thakral \\ Senior Resident, Department of Surgery, University College of Medical Sciences \& Guru Teg Bahadur Hospital
}

